\title{
MELANOMA PRIMÁRIO DO PÁLATO MOLE DE UM CÃO
}

\author{
Rubens Escobar Pires \\ Assistente \\ 1 estampa (2 figuras)
}

Os tumores pigmentados chamaram a atenção dos patologistas desde tempos remotos, pela freqüência e facilidade com que são vistos em sua localização cutânea e por suscitarem problemas de patologia, muitos ainda por elucidar.

A localização primária de tais tumores em outras regióes do organismo, embora rara, veio naturalmente trazer maiores complicações ao assunto, mas, por outro lado, forneceram dados que contribuiram para o esclarecimento de certos pontos obscuros.

Os problemas de patologia dos melanomas, implicam, em sua essência, no conhecimento da formação do pigmento melânico e na filiação das células que o elaboram e veiculam no organismo, tanto em relação a seu evolver ontogenético como quanto à sua filogênese, isto é, aos fatos observados na série animal. E' o assunto motivo de pesquisas neste Departamento, ficando seu relato para trabalhos posteriores, oportunamente.

O fim dêste artigo é registrar uma localização rara de melanoma primário no palato mole de um cão.

Em março de 1938, foi atendido na Clínica Cirúrgica da Faculdade de Medicina Veterinária, pelo Dr. Oswaldo Fabbri, então assistente da cadeira, um animal da espécie canina, do sexo feminino, de 14 anos de idade, cujo proprietário notou há cerca de um mês, sinais de dificuldade respiratória, chegando mesmo a se exteriorizar pela cornagem. Alguns dias após, o animal passou a rejeitar alimentos e ùltimamente vomitava tudo quanto ingeria. Nessas condições foi internado na Clínica e o assistente verificou a presença de um tumor escuro obstruindo quase tôda a faringe, ulcerado e tendo encravado um corpo estranho (osso), que foi imediatamente retirado, melhorando logo sensìvelmente a respiração. Da boca do animal desprendiase forte exalação pútrida. Posto em observação, o animal faleceu alguns dias depois.

A necroscopia efetuada pelo próprio assistente revelou a presença de um tumor ocupando quase tôda a faringe, fazendo saliência na abóbada palatina que apresentava côr cinzento-azulada. Na parte 
saliente na luz da faringe, havia ulcerações maiores ou menores, aprofundando-se algumas na massa tumoral. Os tecidos vizinhos estavam infiltrados pelo tumor, observando-se necrose subseqüente, atingindo os ossos da região que apresentavam, por isso, lesões destrutivas extensas.

Nada mais foi relatado pelo necroscopista, sendo os dados acima os únicos fornecidos.

A peça enviada a êste Departamento constava de uma formação tumoral irregular, bastante friável de côr castanho-escura, recoberta de um lado por mucosa de côr cinzento-azulada, apresentando caracteres anatômicos permitindo identificá-la como pertencendo à parte esquerda do pálato mole, no local onde se continua com a mucosa da bochecha. Essa mucosa reveste grande parte da massa tumoral, apresentando, no entanto, várias soluções de continuidade. Ao corte, o tumor, muito friável, era de côr castanho-escura e com zonas extensas necrosadas. Em certos lugares existia um induto purulento.

EXAME Microscópico: - A mucosa que reveste a maior parte do tumor apresenta, em alguns pontos, suas camadas perfeitamente normais, evidenciando-se, porém, intensa pigmentação das células da basal, em forma de pulverescência castanho-escura no interior de células polimorfas ricas em protoplasma ou sob forma de gotículas livres.

Nos pontos onde a mucosa está aparentemente normal, verifica-se, no derma, infiltração de pequenas células de tipo linfoplasmocitário e um número relativamente grande de vasos neoformados. Em outras zonas, a mucosa, sofrendo pressão da massa tumoral, atrofiouse de todo, reduzindo-se, em alguns pontos, a uma fina lâmina separada do tecido tumoral por tecido conjuntivo fibroso. Noutros pontos, o epitélio adelgaçado envia para as vizinhanças brotos estreitos de células em forma de colunas. Estas a princípio formadas por células basófilas e cilíndricas, à medida que inflitram os elementos vizinhos, se dissociam e as suas células tomam caracteres francamente fusiformes semelhantes aos fibroblastos jovens e assim se confundem com as células que predominam no tumor.

0 tecido tumoral apresenta, em tôdas as partes estudadas, o mesmo tipo de células polimorfas, predominando as fusiformes, de protoplasma abundante e escuro e núcleo vesiculoso, com a cromatina disposta irregularmente. As células estão, às vezes, apertadas umas contra as outras, na maior parte imbricadas, de modo a formar verdadeiros turbilhões. Em outras zonas, as células se apresentam em colunas, tomando, então a forma poligonal, porém, conservando os mesmos caracteres gerais. A maioria das células está cheia de pigmento cas- 
tanho-escuro em forma de poeira, verificando-se, todavia, numerosos depósitos de gotículas de pigmento nos interstícios do tecido. O estroma conjuntivo é escasso e há grande quantidade de vasos de paredes finas. Em vasos maiores nota-se a presença, em sua luz, de massas tumorais compostas de células poligonais, de protoplasma abundante e núcleo vesiculoso.

O tecido tumoral cresceu infiltrativamente, dissociando os componentes teciduais da região, glândulas salivares, músculos, etc., notando-se zonas extensas necrosadas e em alguns lugares infiltração considerável de elementos celulares polimorfonucleares.

Diagnóstico: - Melanoma de células de tipo sarcomatoso (melano-sarcoma) do pálato mole.

A possibilidade do aparecimento de tumores melânicos em qualquer parte do organismo, embora admitida por alguns autores desde que se iniciaram debates sôbre sua origem, foi todavia negada por patologistas como Borst e UNNA que reconhecem como suas únicas localizações a pele e o olho onde normalmente existem células formadoras de pigmento, interpretando as outras localizações como metástases de tumores cutâneos ou orbitários que teriam passado despercebidos ao exame.

Outros, porém, como RIBBERT, consideraram a célula com pigmento, o cromatóforo, de origem mesoblástica tendo capacidade migratória e podendo pois, estabelecer-se em zonas remotas e aí determinar neoformações.

Mais recentemente, MASSON conseguiu, por meio de impregnações, estabelecer relações entre os tumores melânicos da pele e os elementos neuroectodérmicos representados pelos corpúsculos de Meissner. No entanto, a filiação das células névicas permanece obscura; não se conseguiu determinar sua origem nervosa ou ectodérmica em tais preparações.

As idéias predominantes hoje sôbre o problema tendem a um ecletismo, pois, tôdas as origens aventadas acima são admitidas nos diferentes casos.

Para se obter explicação satisfatória para a presença de melanoma no pálato mole é mister recorrer aos conhecimentos que a embriologia nos fornece quanto à formação e origem dos elementos bucofaringeos. Primeiramente deve-se notar que a transição dos elementos ectodérmicos para os endodérmicos não se faz em linha nítida de demarcação, mas, sim, como verdadeira faixa de transição e assim é na boca, onde se verifica que a mucosa da bochecha, pálato e mesmo da faringe possue caracteres dêsse tipo. Por outro lado verifica-se, 
com relativa freqüência, a presença, na mucosa da boca, de manchas pigmentares, sendo isso comum no cão e atribuído pelos criadores, a caracteres raciais peculiares. Assim, mesmo aceitando a origem puramente ectodérmica dos melanomas, há nos dados acima apontados motivo para se considerar possível essa localização primária do tumor.

Por ser a região em apreço séde relativamente freqüente de formações teratóides e mesmo de verdadeiros teratomas, alguns autores julgam, em alguns casos, possível o desenvolvimento de um melanoma a partir de crescimento unilateral como na interpretação dada a certos melanomas do ovário. Essa foi mesmo a interpretação de LENCE para seu caso, pois, fazia-o derivar de restos do órgão de Jacobson.

Em nosso caso, pela precariedade de dados fornecidos, não podemos afastar de todo a possibilidade de ser uma metástase, embora, tal localização nunca tenha sido verificada, apesar da freqüência de metástases nos melanomas, como bem salientou MAUERHOFER.

O estudo dos cortes evidenciou pigmentação aumentada da mucosa, e, em certos pontos, poude-se verificar a existência de uma conexão íntima dos elementos epiteliais da mucosa com o tecido tumoral, parecendo correrem as diferenças morfológicas das células por simples fenômenos de compressão durante o crescimento blastomatoso.

LENCE, em 1937, conseguiu reunir na literatura médica mundial, 36 casos de melanomas primários localizados na boca, tendo 32 dêles sua sede no palato.

A literatura veterinária, em que extensa quanto aos tumores melânicos cutâneos, é pobre quando se trata de outras sedes e semelhante ao nosso, apenas obtivemos a citação de um caso de melanoma do pálato, por OLAFSON, sendo êste provàvelmente, o primeiro caso relatado entre nós.

\section{RESUMO}

Um caso de melanosarcoma do pálato mole de um cão é relatado neste artigo. $\mathrm{O}$ animal apresentou sinais progressivos de dispnéa e disfagia, falecendo um mês após o aparecimento dos sintomas.

Foi verificada a presença de um tumor escuro obstruindo a luz da faringe. O exame histológico revelou tratar-se de um melanosarcoma.

É uma localização rara, tendo sido descrito apẹnas um caso semelhante na literatura veterinária e até 1937 apenas 32 casos com tal localização foram reunidos por LENCE na literatura médica mundial. 
R. Escobar Pires - Melanoma primário, pálato mole - cão

\section{SUMMARY}

A case of melanosarcoma of the soft palate in a dog is reported in this paper.

The animal showed progressive signs of dyspnea and dysphagia, dying one month later.

A brownish tumour was verified obstructing the pharynx. The microscopic examination revealed a melanosarcoma.

It is a rare localization and only one case was described in the Veterinary literature and Lence collected 32 cases with such localization in the medical literature.

\section{BIBLIOGRAFIA}

EwIng, J. - 1941 - Neoplastic diseases. 4th. ed. Philadelphia, W. B. Saunders LENCE, P. - 1937 - Ueber seltene primäre lokalizationen melanotischer Tumoren. Erg. Path., 32: 48-90

Olafson, P. - 1939 - Oral tumors of small animals. Cornell Vet., 29: 222-237. MAUERHOFER, H. - 1931 - Zur Kasuistik des primären malignen Melanoms im Nasenrachen. Zeitschr. f. Laryngol., 22: 16-27 "in" Index Anal. Cancerol., 7: 228-9, 1933 


\section{EXPLICACÃO DAS FIGURAS}

Microfotografia I - Células blastomatosas se originando da parte profunda da mucosa adelgaçada.

Microf́otografia II - Tecido blastomatoso formado por células fusiformes algumas com pigmento e gotículas de pigmento depositadas nos interstícios. 
R. Escobar Pires, Melanoma primário, palato mole - câo

Rev. Fac, Med. Vet. S. Paulo, Vol, s, fasc. $1-2$

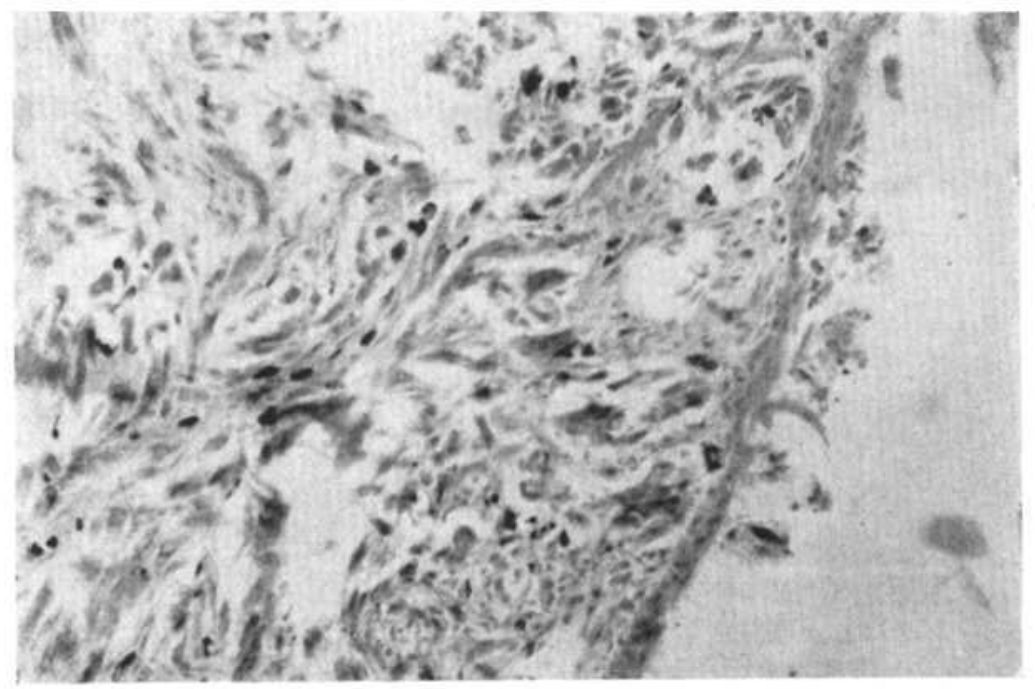

Fig. 1

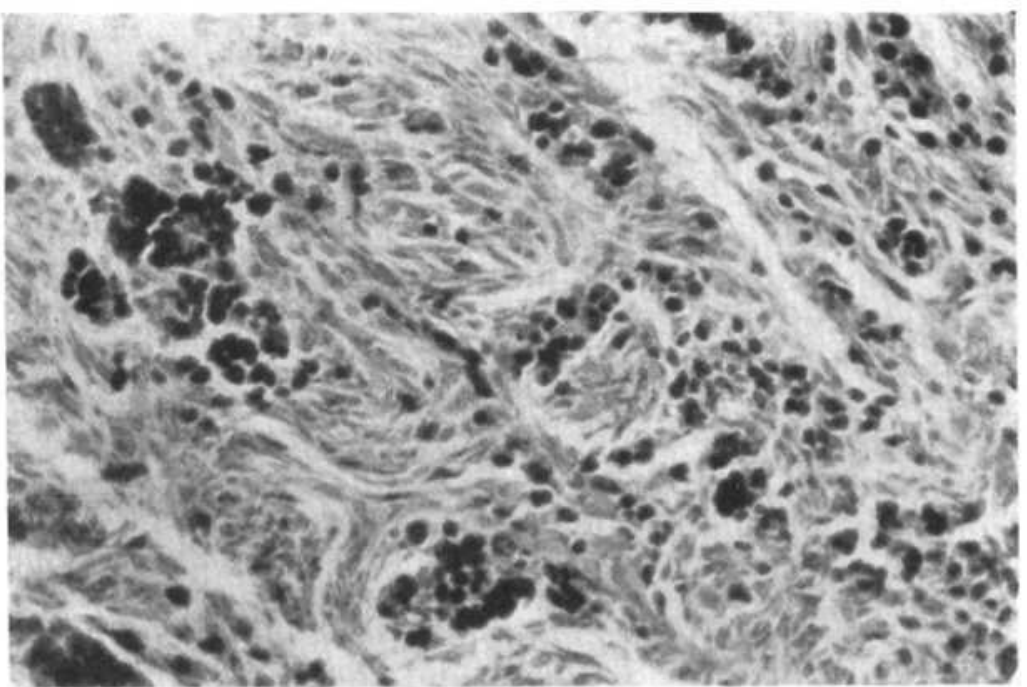

Fig. 2 